\title{
The Effect of Surface Parameters to the Performance of Reverse Engineering Process
}

\author{
Azli Nawawi ${ }^{1}$, Mohd Hadri Mohamed Nor ${ }^{2,}$, Muhamad Amir Hafiz Abdul Halim ${ }^{3}$, and Noor Azizah Sidek $^{2}$ \\ ${ }^{1}$ Faculty of Engineering Technology, Universiti Tun Hussein Onn Malaysia, 86400 Parit Raja, Batu Pahat, Johor, Malaysia \\ ${ }^{2}$ Centre for Diploma Studies, Universiti Tun Hussein Onn Malaysia, 86400 Parit Raja, Batu Pahat, Johor, Malaysia \\ ${ }^{3}$ Faculty of Mechanical and Manufacturing Engineering, Universiti Tun Hussein Onn Malaysia, 86400 Parit Raja, Batu Pahat, \\ Johor, Malaysia
}

\begin{abstract}
Reverse engineering (RE) process is capable of producing CAD models from the existing part without the need of a blueprints or CAD drawing. One of the method to implement $\mathrm{RE}$ is via 3D scanning and the main goal is to produce CAD files that have the highest accuracy possible when compared to the actual parts. Any effort to improve the 3D scanning process should be encouraged because it will save a lot of time and expenses. As a result, this research tends to investigate the effects of surface parameters (Percentage of triangles and Grids resolution) to the performance of RE. Design of Experiments (DOE) method was used and the responses are measured in terms of File size and Error percentage. From the results, it is very interesting to note that the percentage of triangles does not have a significant effect to the file size but plays a major role in minimizing the dimension error. The grids resolution has the significant effects to the file size and error percentage. It can also be concluded that in order to get the best RE performance, the percentage of triangles and file size should be set to maximum. This will ensure that the generated CAD files will have the highest accuracy and from here, high quality products can be made from the RE process.
\end{abstract}

\section{Introduction}

Reverse engineering (RE) is a process to replicate the existing product with the lack of blueprints and documentation [1]. RE is also a field of knowledge that is increasingly in used for various applications such as product development, mechanical engineering, animation, software engineering, electronics and others. $\mathrm{RE}$ is very useful when the blueprint of the original part is not available or outdated. This is due to the fact that $\mathrm{RE}$ is able to capture the geometrical features of the particular part (refer Figure 1). In some cases, RE can assist in speeding up the manufacturing process because the CAD model of a part is constructed using a 3D scanner $[2,3]$.

RE can be divided into two main phase (Digitization and Reconstruction). The former phase is a process to 'capture' the point coordinates of the actual product and this can be done by various types of scanner [4]. The initial geometry is attained in 3 forms (point clouds, polygon model \& sets of images). These condition is depending on the acquirement technique of $3 \mathrm{D}$ scanning [5]. The second phase of RE is the reconstruction phase where the data is managed in a way to create a 3D model. The noise data will be eliminated and other unnecessary data will be filtered [6].

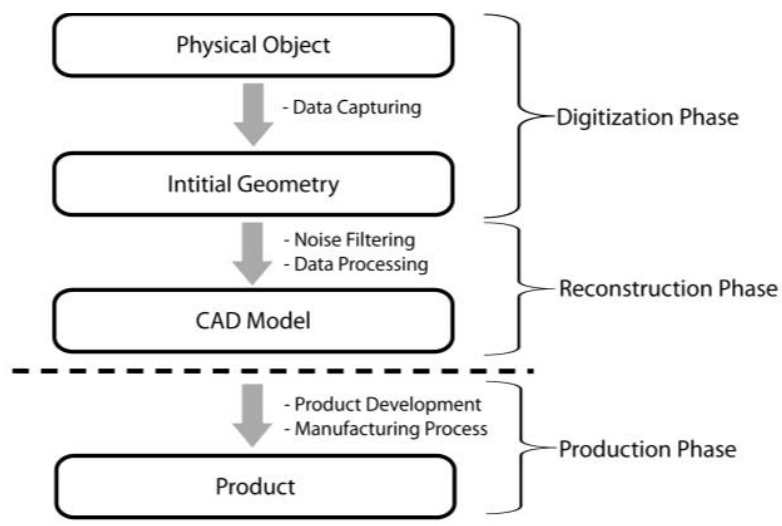

Figure 1. Diagram of reverse engineering process [6]

A 3D scan image is a rendered CAD or STL file that can be viewed in a $2 \mathrm{D}$ or $3 \mathrm{D}$ environment. The geometry of the image can be modified using CAD software packages such as Solidworks, Catia, Geomagic Design and others. The 3D scan images are formed by 3D scanners that have the ability to scan the surface geometry of a part and convert them into point cloud

\footnotetext{
* Corresponding author: $\underline{\text { azle } @ \text { uthm.edu.my }}$
} 
data. From this data, the polygonal mesh can be constructed. The general types of 3D scanners are fixed scanners, manual handheld scanning devices and automatic scanning equipment. The optical scanning system can be divided into three technique such as laser scanning, fringe projection and photogrammetry. The range for scanning size is massive which start from the microscopic objects to the large constructions. The 3D scanning system is good for increasing the productivity and securing the quality in the product development process. This technology also offers greater flexibility and higher resolution, accuracy and speed of measurements $[7,8]$.

The 3D scanning process for small and critical parts is never been an easy task. As a result, some studies focused on determining the best scanning procedure in order to implement the scanning process on the related parts [9]. These line of works also managed to perform the comparison between the white light and blue light scanner [10,11]. The commercial software packages and 3D scanners were also tested and compared in order to assess their performance [9, 12]. The educational institutions and Small and Medium Enterprises (SMEs) are at advantage because the GOM Inspect (freeware) is deemed as acceptable for basic inspection process [9]. Some studies in this area focuses on the critical parts of an aircraft gearbox in order to promote the significance of the developed methodology $[13,14]$.

In the medical related field, the usage of $3 \mathrm{D}$ scanners to facilitate the planning, simulation and orientation of human prosthesis is not new. The 3D scanner is very useful for the planning process of the human prosthesis fabrication because it can speed up the particular process [15]. The implant placement process also benefited from the 3D scanning technologies as it will aid in proposing the best location for the human prosthesis [16]. The 3D scanning system is also embedded in forensics related works for the purpose of documentation of the bodies, living persons and objects [17]. Interestingly, 3D scanners can also be embedded in the forensic post-mortem investigation [18]

The 3D scanning system is also started to be used in measuring the surface integrity after a machining process. This trend has started a decade ago after the related community came into agreement that a $3 \mathrm{D}$ surface geometry inspection will contribute significantly to the process performance [19]. The trends continue with the automation of the 3D scanning process which focuses on the integration of the 3D scanner with an industrial robot. This approach will result in a faster scanning process and also possible to cover a very large volume of scanning jobs [20-22].

The reverse engineering (RE) process is very common in the automotive industry and when it comes to the application of the $3 \mathrm{D}$ scanning system, the main goal is to produce the CAD file that have the best geometry characteristics. This scenario is very crucial when it comes to implementing $\mathrm{RE}$ for the engine components because if the 'generated' CAD file from the $3 \mathrm{D}$ scanning is low in quality, it will results in parts that do not fit well in the engine chamber. This will significantly jeopardized the performance of the engine. As a result, the 3D scanning process should be continuously improved in order to churn out high quality CAD files.

In this research, the surface parameters (Percentage of triangles and Grids resolution) of the generated polygonal mesh will be taken into consideration. These parameters are deemed crucial during the scanned surface editing process because both have the significant effect to the dimension of the CAD file [23]. Thus, this research focuses on investigating the effects of percentage of triangles and grids resolution to the performance of RE process.

\section{Experimental Design}

This research utilized Design of Experiment (DOE) technique for investigating the effect of percentage of triangles and grids resolution to the performance of RE process. In DOE technique, all possible conditions in an experiment are investigated in order to determine the significant factors [24]. DOE can also be used as a tool to understand a particular process because all important factors (parameters) are included during the DOE analysis. As a result, DOE has the ability to identify the key factors for the purpose of quality improvement. Additionally, DOE is also considered as a well-known method for planning large scale experiments because DOE has the ability to generate the required number of runs in order to understand the behaviour of the parameters in study. DOE also has the ability to identify the key strategies for improving the efficiency of a particular system $[25,26]$.

The detailed methodology is shown in Figure 2. The responses selected are the file size and dimension error. The file size represents the complexity of the CAD file because the file size will be large if the details of the surface is 'properly captured'. A CAD file with a huge file size will be more difficult to process because the processing power of a computer should be high in order to 'handle' the file. As a result, this research tends to focus on a way to get a smaller file size without jeopardizing significantly on the quality of the CAD file.

In order to measure the quality of the CAD file in the RE process, a dimension comparison between the existing part and the CAD file will be made. The magnitudes were measured in the form of dimension error which means the larger the percentage of error, the dimensional difference between the actual part and the $\mathrm{CAD}$ model is bigger. Larger percentage of error will contribute to inaccurate and low quality CAD model. It is better to ensure that the value of error as minimum as possible.

The factor for this experiment are the percentage of triangles and grids resolution. These parameters were set into values during the advanced editing process of the scanned surface via the Geomagic Studio software. The levels for percentage of triangles were set at 100, 80, 60, 40 , and 20 . The grids resolutions was set based on these levels: 10, 20, 30, 40 and 50. 
The 3D scanning process was performed using ATOS 3D scanner (refer Figure 3) and the surface editing process was done in two stages. The initial editing (filtering, close holes and surface repair) was performed in the ATOS software and the advanced editing process and surface formation were done in Geomagic Studio software (refer Figure 4). In the Geomagic software, the values of percentage of triangles and grids resolution were set and then the NURBS surface was formed. Once completed, the surface then need to be converted to the .IGES format. This stage is crucial to make sure that it can be handled and manipulated in Solidworks environment (Figure 5).

As mentioned before, the responses for the DOE technique are the file size and dimension error. For the latter, there are three selected dimensions which are internal hole diameter (D1), distance between two holes (D2) and external diameter (D3). The visual descriptions of D1, D2 and D3 are presented in Figure 6, 7 and 8 respectively. The actual dimension values for D1, D2 and D3 can be referred in Table 1. The actual dimensions were compared to the dimensions taken in the Solidworks software and finally converted to the dimension errors (in percentage forms). The low quality $\mathrm{CAD}$ files depicted by higher error percentage values.



Figure 2. Investigating the effect of percentage triangles and grids resolution to the reverse engineering process

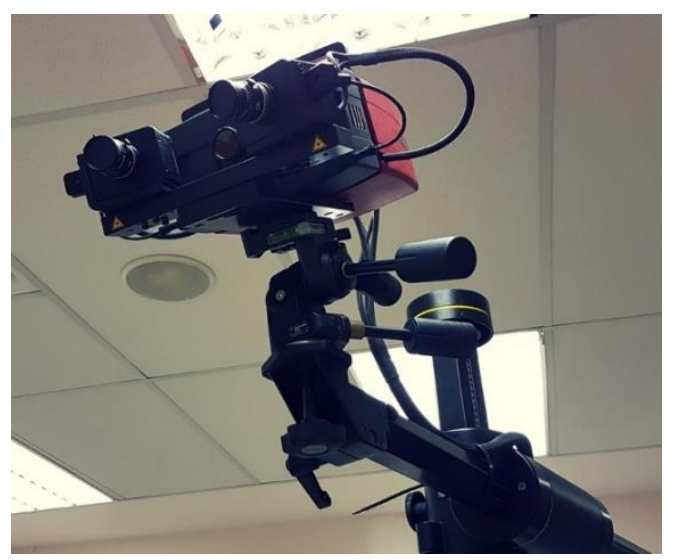

Figure 3. ATOS 3D Scanner 


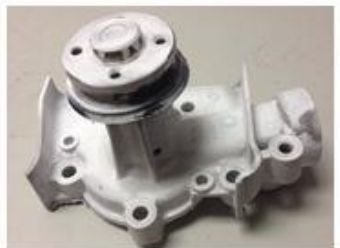

(a)

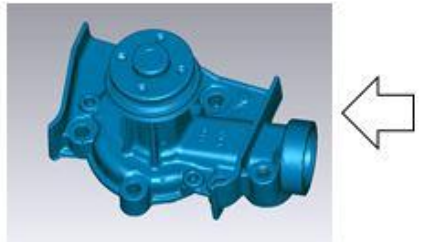

(d)

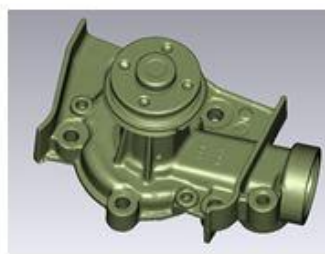

(e)

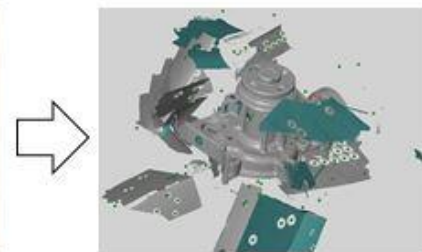

(b)

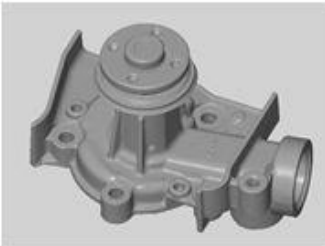

(c)

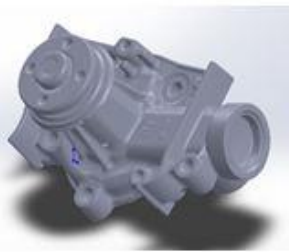

(f)
Figure 4. 3D scanning process of automotive water pump

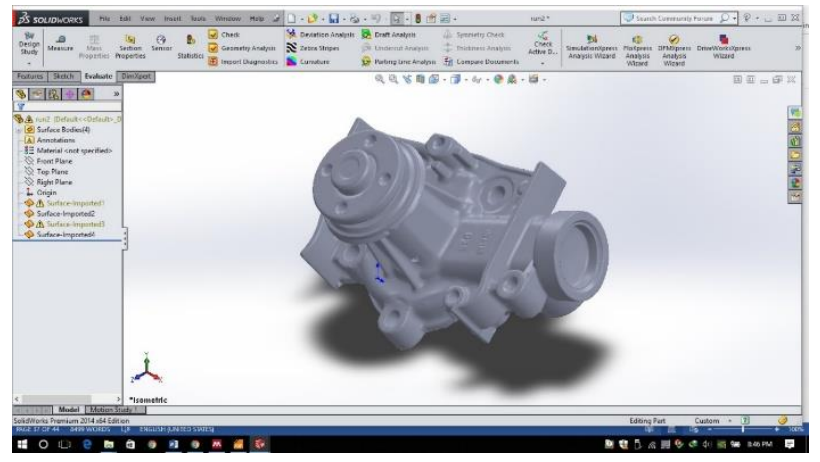

Figure 5. The completed CAD model in Solidworks software. This model is ready for measurement

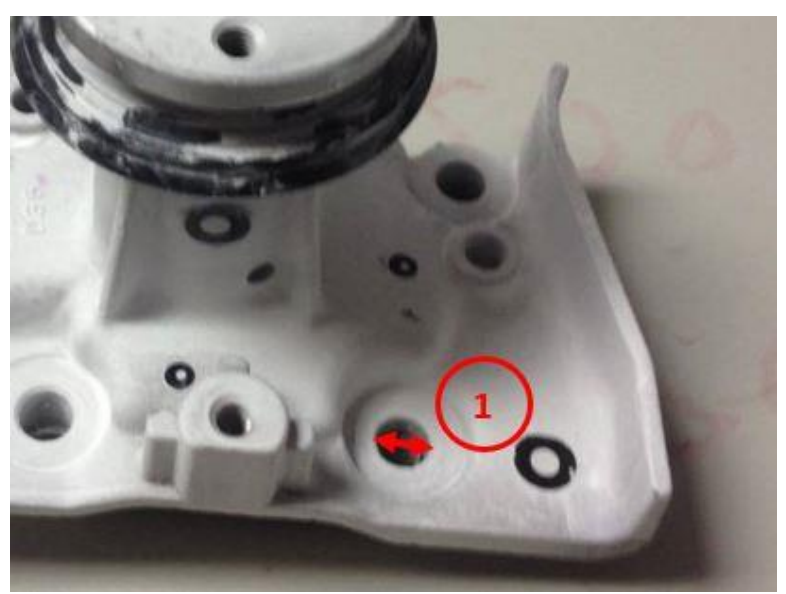

Figure 6. Internal hole diameter (D1)

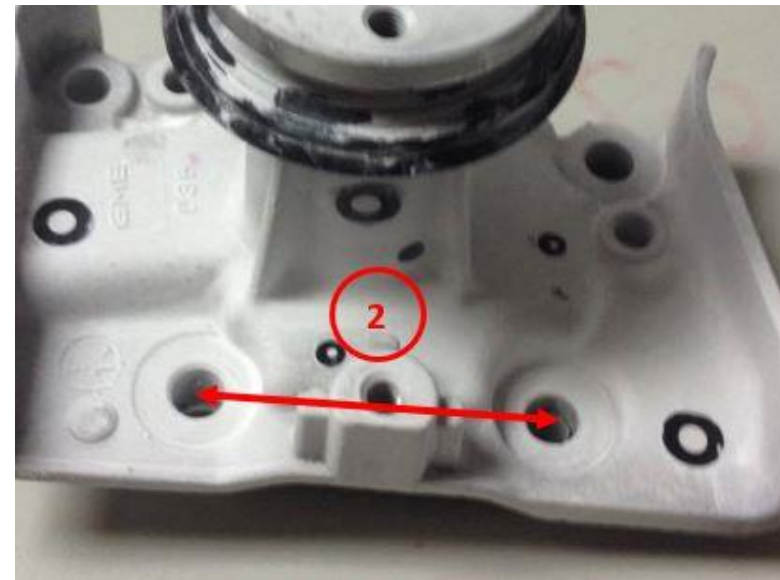

Figure 7. Distances between two holes (D2)

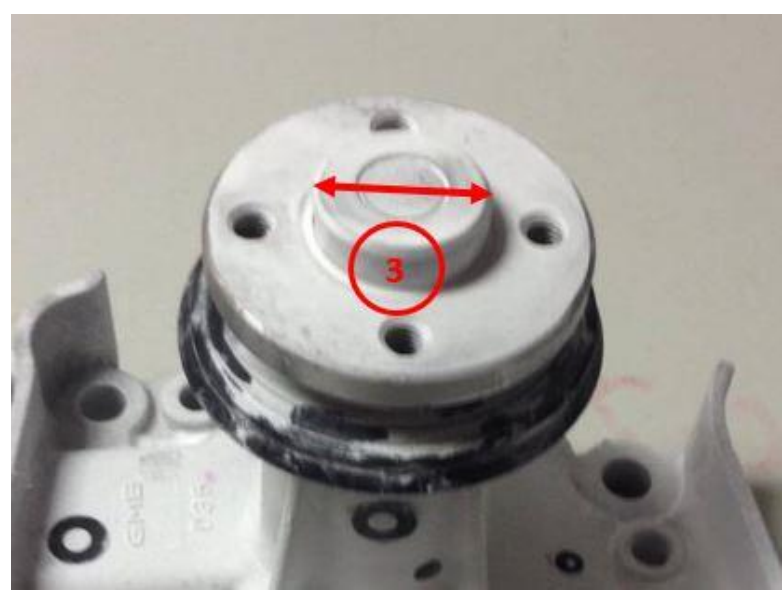

Figure 8. External diameter (D3)

The data sheet used in this research was generated using Minitab software under the DOE feature. Based on the number of factors and responses, the DOE were set for 25 runs.

Table 1. Measurement data for actual part using FMM (Flexible Measuring Machine)

\begin{tabular}{|c|c|c|}
\hline $\begin{array}{c}\text { No of } \\
\text { Dimension }\end{array}$ & Feature Name & $\begin{array}{c}\text { Flexible Measuring } \\
\text { machine (mm) }\end{array}$ \\
\hline D1 & $\begin{array}{c}\text { Internal hole } \\
\text { diameter }\end{array}$ & 9.9175 \\
\hline D2 & $\begin{array}{c}\text { Distance between } \\
\text { two holes }\end{array}$ & 48.3255 \\
\hline D3 & External diameter & 23.2555 \\
\hline
\end{tabular}

\section{Results and Discussion}

Upon completing the experiments, the completed data sheet can be referred in Table 2. These data were analysed using Minitab software via the DOE feature. 
Table 2. The completed data sheet for the DOE

\begin{tabular}{|c|c|c|c|c|c|c|}
\hline $\begin{array}{l}\stackrel{8}{z} \\
\Xi \\
\underline{E}\end{array}$ & 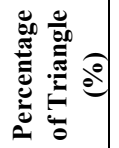 & 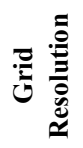 & 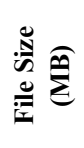 & 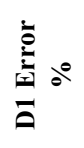 & 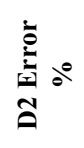 & 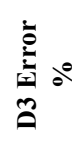 \\
\hline 1 & 60 & 20 & 29.3 & 6.77 & 1.39 & 3.59 \\
\hline 2 & 100 & 40 & 150 & 7.63 & 1.23 & 2.92 \\
\hline 3 & 40 & 40 & 157 & 7.22 & 1.76 & 0.45 \\
\hline 4 & 40 & 10 & 10.3 & 7.25 & 1.48 & 2.50 \\
\hline 5 & 100 & 50 & 266 & 7.57 & 1.23 & 0.73 \\
\hline 6 & 20 & 40 & 163 & 6.13 & 0.28 & 2.18 \\
\hline 7 & 20 & 50 & 292 & 6.08 & 0.12 & 2.43 \\
\hline 8 & 40 & 50 & 281 & 7.19 & 1.40 & 0.39 \\
\hline 9 & 80 & 10 & 9.7 & 6.51 & 1.57 & 3.63 \\
\hline 10 & 80 & 20 & 29.8 & 6.19 & 1.55 & 2.73 \\
\hline 11 & 100 & 10 & 10.2 & 7.96 & 1.29 & 1.58 \\
\hline 12 & 100 & 20 & 31.2 & 7.81 & 1.27 & 0.72 \\
\hline 13 & 100 & 30 & $\begin{array}{l}92.8 \\
\end{array}$ & 7.66 & 1.24 & 1.03 \\
\hline 14 & 60 & 10 & 11 & 6.18 & 1.72 & 0.97 \\
\hline 15 & 40 & 30 & 96.9 & 7.24 & 1.42 & 2.83 \\
\hline 16 & 20 & 20 & 32.2 & 6.36 & 1.80 & 3.53 \\
\hline 17 & 20 & 30 & 99.4 & 6.20 & 1.79 & 2.46 \\
\hline 18 & 40 & 20 & 32.1 & 7.30 & 1.45 & 0.85 \\
\hline 19 & 60 & 30 & 99.2 & 5.75 & 1.73 & 0.88 \\
\hline 20 & 60 & 50 & 285 & 5.61 & 2.21 & 2.71 \\
\hline 21 & 80 & 40 & 144 & 5.87 & 1.33 & 2.35 \\
\hline 22 & 60 & 40 & 160 & 5.67 & 0.37 & 2.22 \\
\hline 23 & 80 & 50 & 256 & 5.78 & 1.32 & 2.30 \\
\hline 24 & 80 & 30 & 88.7 & 5.92 & 1.34 & 2.43 \\
\hline 25 & 20 & 10 & 9.8 & 6.58 & 1.80 & 3.20 \\
\hline
\end{tabular}

Figure 9 shows the main effects plot for file size which focuses on the best setting for both factors. It can be concluded that in order to get the smallest file size, the percentage of triangles and grids resolution should be set at 80 and 10 respectively. From this figure, it can be seen that the percentage of triangles do not give a significant effect to the file size because the trend line is almost flat.

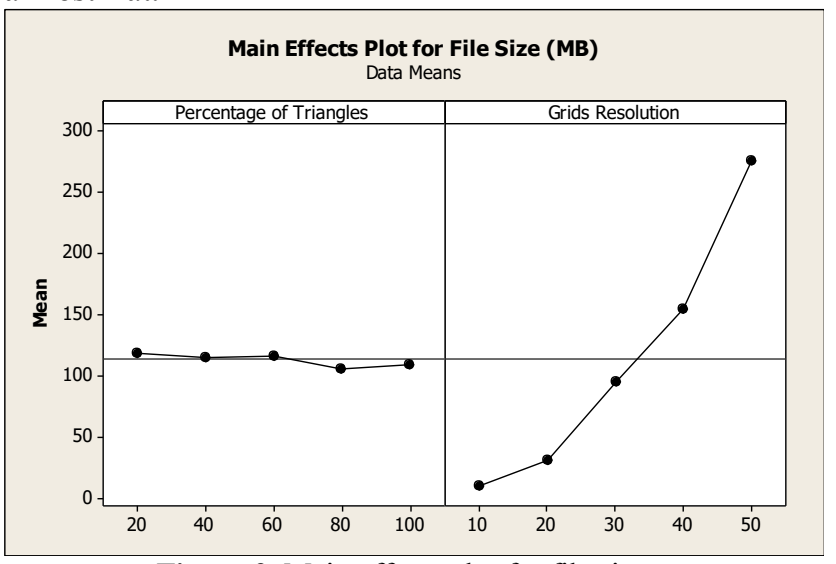

Figure 9. Main effects plot for file size

A contour plot is very useful for determining the best region for parameter tuning. Figure 10 shows the contour plot for the file size and the lightest green region is the smallest file size region. From the figure, it can be seen that the file size is the smallest when the grids resolution is set to less than 22 . As for the percentage of triangles, any value will do because it does not affect the file size in a very significant way.

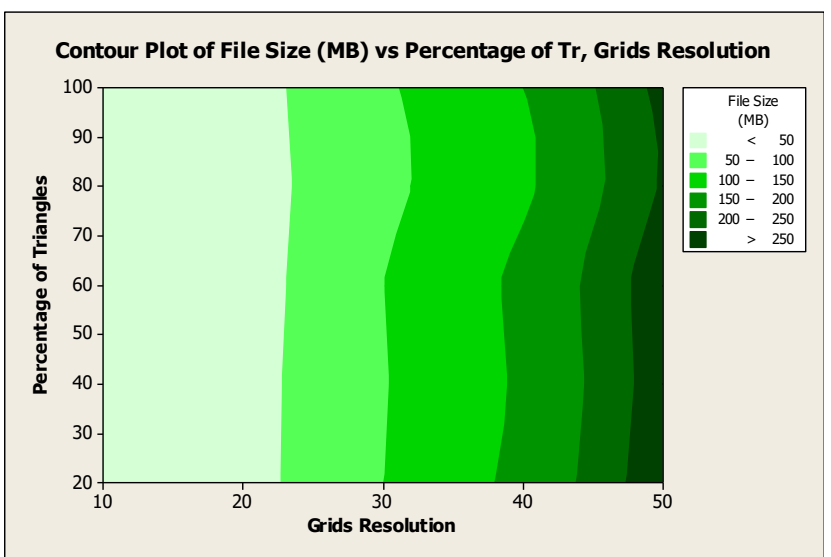

Figure 10. Contour plot of file size against the parameters

Figure 11 is the main effects plot for the error percentage of D1. Based on Figure 6, D1 is the internal diameter of a small hole in the water pump. The reason for the author to choose D1 is due to its importance in the assembly process of the water pump. From Figure 11 , it can be concluded that the percentage of triangles give a significant impact to D1 because the slope is really steep. From here, it can be said that the percentage values in the range of 60 to 80 will result in a lower dimension error for D1. As for the grids resolution, the slope is flat in two region (10 to 20 and 30 to 50 ). However, the grids resolution value of 50 will produce less dimension error for a small hole like D1.

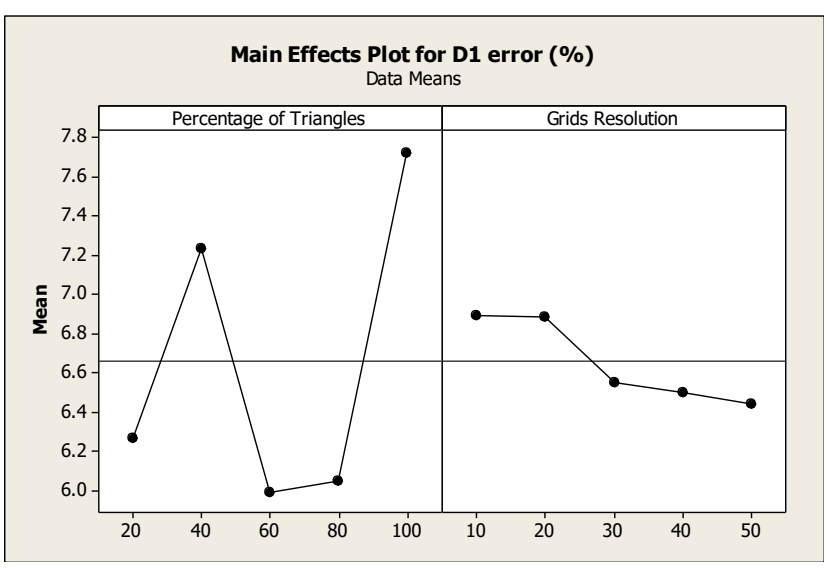

Figure 11. Main effects plot for D1 error

Based on the contour plot for D1 (Figure 12), the region with the lowest error is when the percentage of triangles is set from 60 to 80 and the grids resolution is set from 25 to 50 . The region that should be avoided is when the percentage of triangles is set to more than $95 \%$. 


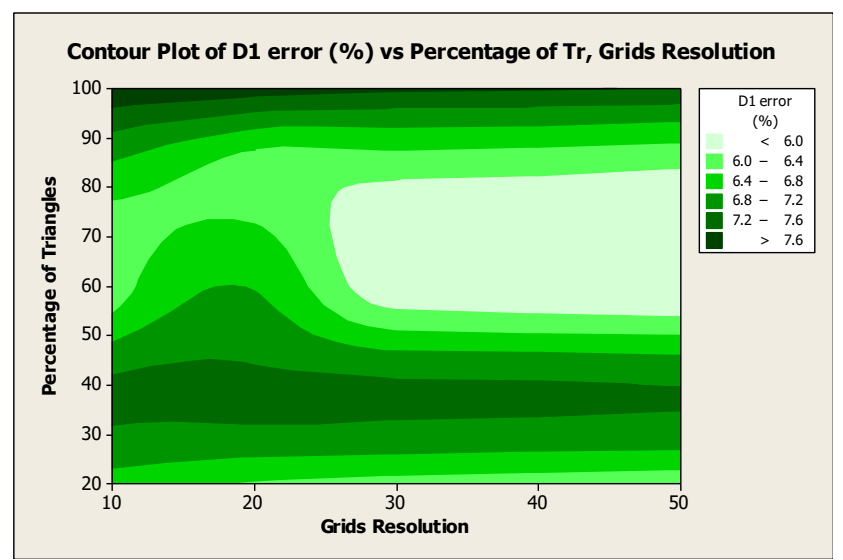

Figure 12. Contour plot of D1 error against parameters

D2 is the length between two holes (refer Figure 7) and it can be a representative for exploring the effect of both factors to the dimension length between two holes. Figure 13 shows the main effects plot for the percentage error for D2. From the figure, it can be seen that the best setting for the percentage of triangles is at $20 \%$. This is very interesting because as the percentage of triangle become lower, the surface will have a significant change in terms of the surface details. The grids resolution have a significant effect to D2 because of the steep slope. From the figure, the best setting for grids resolution is 40.

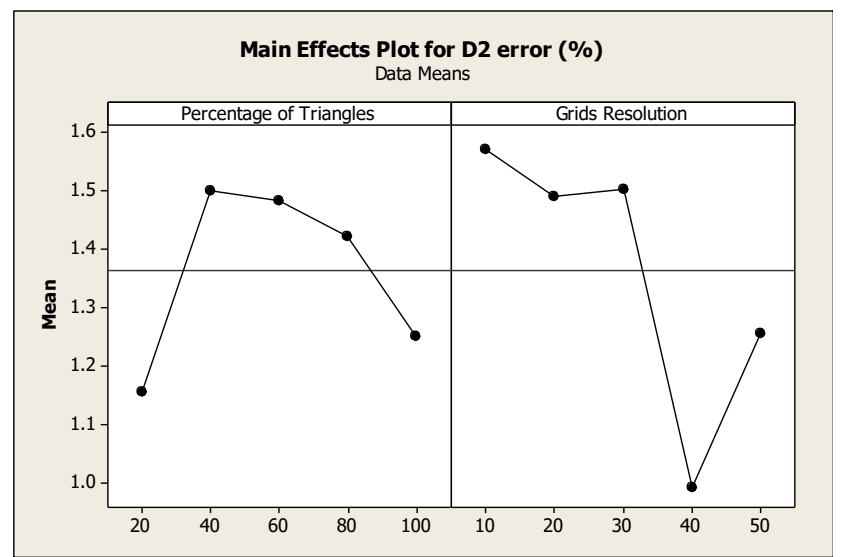

Figure 13. Main effects plot for D2 error

The contour plot for D2 is shown in Figure 14. The best region for minimizing the dimension error of $\mathrm{D} 2$ is when the percentage of triangles is set to less than 25. As for the grids resolution, it should be set at more than 40 .

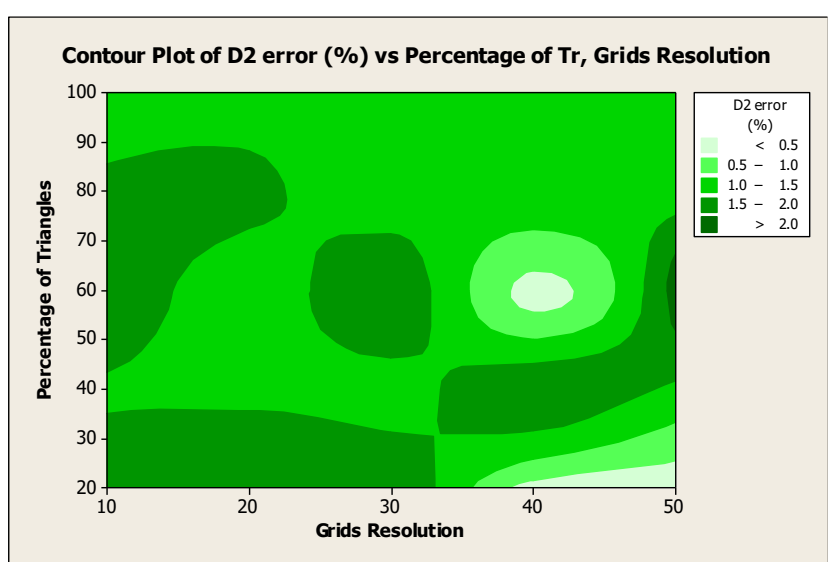

Figure 14. Contour plot of D2 against parameters

Figure 15 shows the main effects plot for D3. From Figure 8, it can be seen that D3 is the external diameter of a feature on the water pump. There are two good setting for the percentage of triangles (40 \& 100). However, from the figure, it can be seen that the 100 is slightly lower than the 40 . The grids resolution also has a significant effect to the percentage error of D3 and the best setting is 50 because it will produce less dimension error. The lower the percentage of dimension error, the produced CAD model will be more accurate and higher in quality.

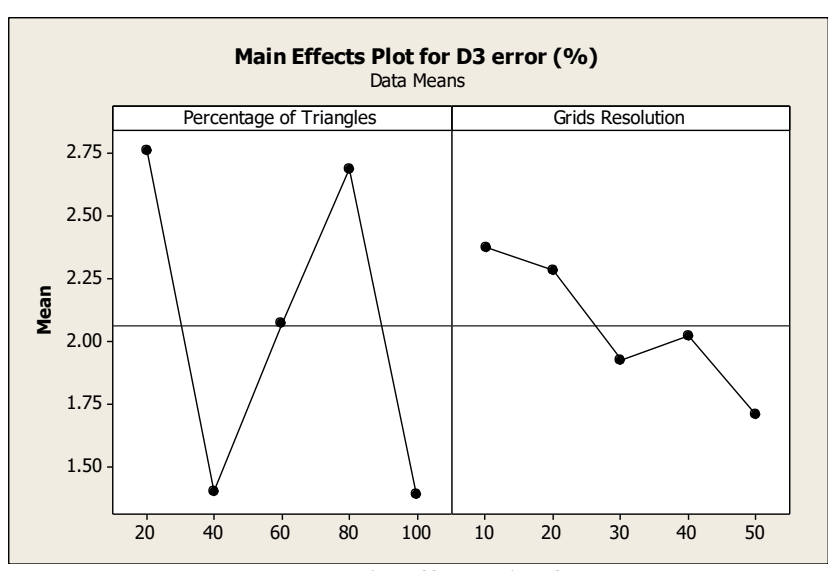

Figure 15. Main effects plot for D3

To assist in the decision making process on the parameter tuning for scanning part with prominent external diameter, Figure 16 can be used. Based on the figure, the 'safest' region is when the percentage of triangles and grids resolution is set at $30-40$ and $40-50$ respectively. 


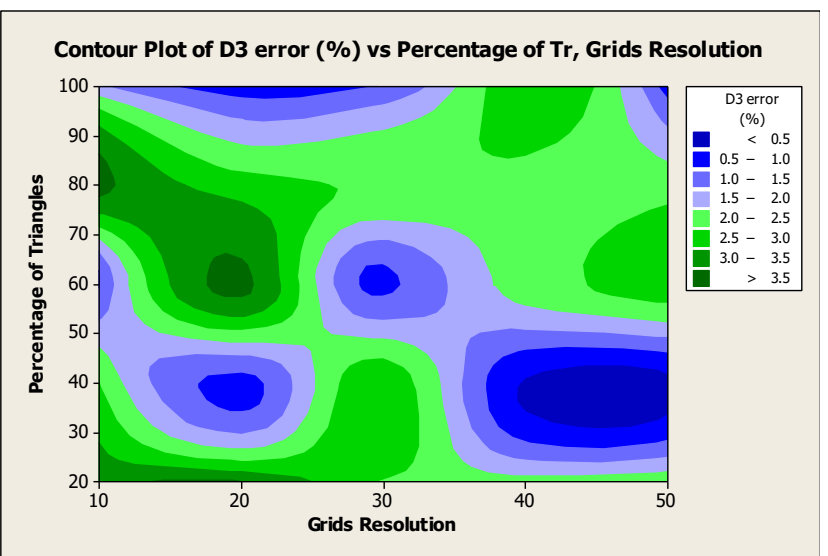

Figure 16. Contour plot of D3 error against parameters

The summary from all the plots can be seen in Table 3. It can be concluded that for main effects plot for all three dimensions, both the factors (parameters) significantly affected the percentage error. The percentage of triangles for D1, D2 and D3 show fluctuate patterns and the value for percentage of triangles to get the lowest percentage error are 60,20 and 100 respectively. The grid resolution for all three dimensions is likely to have the same pattern which can be concluded that the higher the grid resolution, the lower the percentage error.

Table 3. The best setting parameters for all three dimensions to get the lowest percentage error

\begin{tabular}{|l|l|l|l|l|}
\hline \multirow{2}{*}{ Factor } & \multicolumn{4}{|l|}{ Best parameter setting } \\
\cline { 2 - 5 } & $\begin{array}{l}\text { File Size } \\
\text { (MB) }\end{array}$ & $\begin{array}{l}\text { D1 Error } \\
\mathbf{\%}\end{array}$ & $\begin{array}{l}\text { D2 Error } \\
\%\end{array}$ & $\begin{array}{l}\text { D3 Error } \\
\%\end{array}$ \\
\hline $\begin{array}{l}\text { Percentage of } \\
\text { Triangle (\%) }\end{array}$ & 80 & 60 & 20 & 100 \\
\hline Grid Resolution & 10 & 50 & 40 & 50 \\
\hline
\end{tabular}

From Table 3, it can be seen that majority of the setting for the percentage of triangles is in the higher region (more than 60). From here, it can be concluded that to get a higher quality and more accurate CAD model, it is best to set the percentage of triangles to more than 60 .

The grids resolution is directly proportioned to the quality of the CAD models. As the resolution go higher, the details of the surface are 'properly-captured'. From the table, the lowest grids resolution will produce smallest file size. This is very useful if the scanned surface will be used for the less critical applications such as making souvenirs, exhibitions and decorations. To produce a high quality CAD model, the grids resolution should be set to the highest possible. This will make sure the surface model is accurate and it will be useful for using the scanned surface to machine or 3D-print a very critical machine part. From here, it can be said that the setting for the percentage of triangles and grids resolution is based on the end product or application of the reverse engineering process.

\section{Conclusion}

This research tends to investigate the effects of surface parameters to the performance of the RE. The performance of RE process will be measured in terms of file size and error percentage. The parameters (factors) in consideration are the percentage of triangles and grids resolution. From the results, it can be concluded that the percentage of triangles does not have a significant effect to the file size. This is good sign because the percentage of triangles is significant when it comes to the error in dimensions. The grids resolution, in the other hand, plays a significant role in determining the file size. Higher grids resolution will lead to larger file size. This will make the $\mathrm{CAD}$ file become more difficult to process because the processing power of the computer should be high. However, a higher grids resolution will produce less dimension error.

In order to compare the dimension of the actual part and the scanned surface (CAD file), the term error percentage was used. From the research, both factors do play a significant effects when it comes to the error percentage. It can also be concluded that in order to get the desired result, which is the lower error percentage, both factors should be set to their maximum values (100 for percentage of triangles and 50 for the grids resolution).

Finally, in order to set the values for both factors, the first point to know is the application of the generated CAD file from the $3 \mathrm{D}$ scanning process. If the file is to be used for a highly critical task such as making an engine components, gearbox, medical appliances and others, the user should set the values of percentage of triangles and grids resolution to the maximum as possible. This will ensure minimum dimension error between the actual part and the scanned surface.

It is also worth to mention that the right setting for the surface parameters is very crucial because it can ensure a high quality CAD model produced from the RE process. The right setting can also save a lot of time and effort as it will lead to the 'first time correct' approach. A wrongly set surface parameters will waste a lot of time because the 3D scanning process is a very time consuming process. This scenario will become worse if the surface editing process is taken into account.

This research is funded by UTHM under the Short Term Grant (STG Vot U361). Additionally, the authors would like to thank UTHM for providing the equipment and software utilized in this research.

\section{References}

1. M. Paulic, T. Irgolic, J. Balic, F. Cus, A. Cupar, and T. Brajlih, Procedia. (2014).

2. V. Raja and K. Fernandes, Reverse engineering: an industrial perspective, Springer Science \& Business Media (2007).

3. A. Gameros, L. De Chiffre, H.R. Siller, J. Hiller, and G. Genta, CIRP J. Manuf. Sci. Technol. 9, 116124 (2015). 
4. W. Wang, Reverse engineering: Technology of reinvention, CRC Press (2010).

5. V. Raja and K. Fernandes, Reverse engineering system, Springer Science \& Business Media (2007).

6. S. Rooppakhun and N. Chantarapanich, Forensic Medicine - From Old Problems to New Challenges , Creative Commons (2011).

7. K. Fuentes and K. Donaldson, 2016 NCUR Proceedings (2016).

8. G. Constantinou, G. Wilson, S. Sadeghi-Esfahlani, and M. Cirstea, 2017 International Conference on Optimization of Electrical and Electronic Equipment (OPTIM) \& 2017 Intl Aegean Conference on Electrical Machines and Power Electronics (ACEMP), 1083-1088. IEEE (2017).

9. P. Minetola, L. Iuliano, and F. Calignano, Comput. Ind. 67, 54-71 (2015).

10. L. Morovič and P. Pokorný, Adv. Mater. Res. vol. 468-471, 2269-2273 (2012).

11. J. Vagovský, I. Buranský, and A. Görög, Procedia Eng. 100, 1198-1206 (2015).

12. W. Renne, M. Ludlow, J. Fryml, Z. Schurch, A. Mennito, R. Kessler, and A. Lauer, J. Prosthet. Dent. 118, 1, 36-42 (2017).

13. A. Marciniec, G. Budzik, T. Dziubek, and M. Grzelka, J. KONES (2012).

14. G. Budzik and T. Dziubek, Diagnostyka. 1, 51-56, Polish Society for Technical Diagnostics (2015).

15. C. von Wilmowsky, B. Bergauer, E. Nkenke, F.W. Neukam, W. Neuhuber, M. Lell, A. Keller, S. Eitner, and R.-E. Matta, J. Cranio-Maxillofacial Surg. 43, 8, 1335-1339 (2015).
16. F. Jonkergouw, F. Allé, K. Chellaoui, J. Vander Sloten, and D. Vangeneugden, Med. Eng. Phys. 38, 12, 1513-1517 (2016).

17. L.C. Ebert, P. Flach, W. Schweitzer, A. Leipner, S. Kottner, D. Gascho, M.J. Thali, and R. Breitbeck, J. Forensic Radiol. Imaging. 5, 1-7 (2016).

18. P. Urbanová, P. Hejna, and M. Jurda, Forensic Sci. Int. 250, 77-86 (2015).

19. D. Przestacki, R. Majchrowski, and L. MarciniakPodsadna, Appl. Surf. Sci. 388, 420-423 (2016).

20. A. Adán, B. Quintana, A. Vázquez, A. Olivares, E. Parra, and S. Prieto, Sensors. 15, 5, 11551-11574, (2015).

21. S. Kriegel, C. Rink, T. Bodenmüller, and M. Suppa, J. Real-Time Image (2015).

22. T. Koutecký, D. Paloušek, and J. Brandejs, Opt. Int. J. Light Electron Opt. 124, 18, 3705-3709 (2013).

23. V. Sequeira, K. Ng, E. Wolfart, J.G.M. Gonçalves, and D. Hogg, ISPRS J. Photogramm. Remote Sens. 54, 1, 1-22 (1999).

24. M. Packianather, F. Chan, C. Griffiths, S. Dimov, and D. Pham, Procedia CIRP (2013).

25. P. Alotto, M. Gaggero, and G. Molinari, 3, 22, IEEE Trans. on Magnetics (1997).

26. F. Dobslaw, Proceeding of the International Conference on Computer Mathematics and Natural Computing 2010, WASET (2010). 